\title{
The Sense of Society
}

\section{LLOYD E. SANDELANDS}

\begin{abstract}
Human society is unique in the animal kingdom in the degree to which it depends upon its members reflective awareness of self and society. Whereas much has been learned about the sense of self, little is known about the sense of society. This paper develops three points about the human sense of society: First, this sense is a feeling of life, what German writers have called Lebensgefuhl. The paper begins by defining feeling as a psychical moment or 'phase' of bodily activity. The paper later develops the idea that what is felt of society is always an embodiment of its vital form; its social life. Second, the sense of society is a feeling of society, as distinct from a feeling in society and from a feeling of self. The middle third of the paper distinguishes these concepts and links the feeling of society to writings of Freud and Durkheim in which elements of this feeling are found. And third, feelings of society prominently include participation, love, and play. These feelings, which are embodiments of vital social form, are illustrated and discussed in the penultimate section of the paper. Having registered these three points, the paper concludes with a brief summary and discussion of implications for expanding the scope of inquiry in social science.
\end{abstract}

Only a very advanced primate could smile, and mean it. With this social grace comes an important clue about human social life. Namely, that it rests upon a sense of society. The smile is among our most elementary and important sociable acts. It is a great leveler that makes interchange possible over great social distance. It says in effect, 'I meet you as a person like myself, the two of us linked as parts of a greater social whole.'

To hear primatologists and historians tell it, primate society is all love and hate. de Waal (1982), for example, finds in the social life of chimpanzees a dialectic of contest and conciliation. Power plays upset colony alliances and 
create the need and occasion for reconciliations that set the stage for new power plays. For all the energy and spectacle of the dominance contest, the colony spends most of its time patching up social relationships and mending fences. The history of human society is no less a litany of ambition, conflict, and reconciliation. Therein arises all that is great and mean in human life-from the barest kindness to the atrocity of the Holocaust. Indeed, were it not for politics and the picking-up afterwards, one wonders what would be left to historians to talk about.

A longstanding question in social science is whether primate and especially human societies are linked to other animal societies in a continuous chain of being, or whether they present new features which distinguish them as a great leap from what came before. The debate over this question, like so many debates in social science, does not illuminate facts so much as express values (Haraway, 1991). There are deep similarities between non-primate and primate societies to be sure - among these, collective defense, pack hunting, sexual dimorphism, and division of labor-but impressive differences as well (Wilson, 1975). These differences appear most clearly, or even exclusively, in our own human kind. With hominid development of erect bipedalism, continuous sexuality, a larger and more specialized brain, opposable thumb, and articulated vocal tract, came a leap in the capacity to symbolize, and with it, an unprecedented capacity for association. In what was perhaps a unique saltatory development, the human animal could commune with its own in mime, dance, and choric shout, and could, by combining these, develop what we today call language (Langer, 1982; Sheets-Johnstone, 1990). These new social capacities brought new social processes and forms.

The emergence of a substantial symbolizing capacity along our branch of the primate line was a decisive event in the evolutionary history of animal societies (more anthropocentric writers might call it the decisive event). With the ability to symbolize came reflective awareness of society as a whole - a sense of society. With the ability to symbolize came also awareness of self, awareness of others, and awareness of personal relations. Because we can think about our behavior in relation to others, we can cooperate in voluntary systems of action. We are capable of formal organizations (Mead, 1934). ${ }^{1}$ Indeed, we can make any society we want; a blood pact, wedding vow, Madonna fan club, Knights of Columbus, General Motors, PTA, Daughters of the American Revolution, Alcoholics Anonymous, Greenpeace.

However, and as nothing is free in evolution, we pay for our varied social life, in daily dues of anxiety and guilt. We worry about how we are seen by others, about whether they like us, about what is fair, right, and good, and about how we fit into the scheme of things. And we feel regret when we cross the lines we have drawn for ourselves. No other animal knows the trouble we see. None have the same sense of society, nor in consequence the same concern for self in relation to others. Lions, for example, recognize others of their pride 
(by chemical scent), but have no sense or idea of the pride as a whole, much less of themselves as individuals in relation to it. Theirs is a different order of society altogether. The same goes for the 'pecking order' of chickens. Chickens care only for themselves, and not a whit for the flock. Hierarchy is a condition but not a concern of life. Chickens don't care about social order and don't mend fences. A chicken wouldn't smile even if it had the lips. ${ }^{2}$

There can be no doubt about the significance of the human sense of society. Without it, social life as we know it could not exist. There could be no personal identity, no sympathy for others, no fairness, no reciprocity, no formal organization, and no morality - in short, none of what makes us unique in the animal kingdom. And yet, for all its significance, little is known about the sense of society. Indeed, far more ink has been spilled on the sense of self, even though this sense is secondary and derivative of the sense of society. This paper is about the sense of society behind the human smile. Its aim is philosophical; to develop an idea about this sense that can contribute to an understanding of social life.

The paper develops three points about the human sense of society: First, this sense is a feeling of life, what German writers have called Lebensgefuhl. The paper begins by defining feeling as a psychical moment or 'phase' of bodily activity. The paper later develops the idea that what is felt of society is always an embodiment of its vital form; its social life. Second, the sense of society is a feeling of society, as distinct from a feeling in society and from a feeling of self. The middle third of the paper distinguishes these concepts and links the feeling of society to writings of Freud and Durkheim in which elements of this feeling are found. And third, feelings of society prominently include participation, love, and play. These feelings, which are embodiments of vital social form, are illustrated and discussed in the penultimate section of the paper. Having registered these three points, the paper concludes with a brief summary and discussion of implications for expanding the scope of inquiry in social science.

\section{THE CONCEPT OF FEELING}

Perhaps the most under-appreciated fact about the human sense of society is its connection to feeling. Only in Whitehead's philosophy of organism do we find knowledge identified with feeling. "(I)f we wish to understand the relation of our personal experience to the activities of nature," wrote Whitehead (1934, p. 76), "the proper procedure is to examine the dependence of our personal experiences upon our personal bodies." Following Whitehead, we begin from the premise that social life is known primarily as a bodily experience; as feeling.

Langer (1967) saw that feeling is a phase principle. Feeling is how vital processes beyond threshold intensities appear in awareness. All feeling is feeling of life; what phenomenologists such as Scheler and Buytindijk call Lebensgefuhl. Feeling is to organic processes as the red glow of super-heated iron is to 
molecular and atomic dynamics. It is an aspect, a psychical moment, of the living body; a property of life. In this idea we hear an echo of James: "Our whole cubic capacity is sensibly alive; and each morsel of it contributes its pulsations of feeling, dim or sharp, pleasant, painful, or dubious, to that sense of personality that every one of us unfailingly carries with him." James, 1890; p.451].

Feeling identifies activity. What is felt is not a particular object or thing, but the form of activity. Feeling emerges from organism. Feeling is not as Schacter \& Singer (1962) suggest; a generic state of autonomic arousal distinguished by circumstantial thoughts. Rather, it is the psychic aspect of activity. As CampbellFisher (1951) notes, what we feel in an emotion is a definite "pattern of kinaesthesis (felt movement) and coanaesthesis (sensations of pressure, temperature, or those peculiar to the internal organs)" (p. 12). Some feelings are allied with a narrow range of activity forms, others with a broader range of activity forms. For example, whereas the feeling of 'anger' probably has a circumscribed organic morphology (see, e.g., James, 1890; Lakoff, 1987; pp. 380-415); the feeling of 'being alive' probably has the most general organic morphology of all. Feeling can be inferred from the form of activity and the form of activity can be inferred from feeling. ${ }^{3}$

As an example of the identity of feeling and the form of bodily activity, Campbell-Fisher (1951) details the case of grief as follows:

To one in prolonged grief it is not the constant unpleasantness that most clearly stands out, but the long level stretches of everything almost motionless in some dead monotony of flatness. To the grief-stricken, all reactions to stimuli one meets seem automatically to take their place on this level. There are not sudden ascents or descents of feeling - all is on one unchanging and low lying plane. The explanation of this feeling is to be sought in the bodily reactions which go along with grief, or in a sense constitute it. Lange has well described these: the paralyzing effect on the voluntary muscles, seen in the sagging face; the weariness, with movements made slowly, heavily, unwillingly, with exertion, dragging feet, hanging arms; the grieving person sitting still sunk in himself and silent, neck bent, head bowed down. The characteristic words are "downcast," "oppressed," "laderr;" "weight of sorrow," to "bear up under" (while one must keep anger down). The succumbing to sorrow may be a literal inability to stand upright so that the victim sinks or leans on surrounding objects or throws himself flat. Lange describes also the diminution of function in the involuntary muscles, resulting in pallor and shrunkenness, and of inner organs so that decreasing secretions make the mouth dry, the tongue sticky, and sorrow bitter, (pp. 12-13).

The form of felt activity need not be described in physiological terms (see, Sandelands, 1988). For purposes of analysis, felt activity can be described in a variety of ways; as a physical syndrome (e.g., James, 1890), a system of motives (e.g., Buck, 1985), or even a structure of thought (e.g., Festinger, 1957). Thus Arnheim (1966, p. 310) could describe emotion in mentalistic terms as "... the tension or excitement level, produced by the interaction of mental forces. In the 
mechanisms of the mind, emotion is the stress caused by the tractions and pressures that constituted mental activity."

A considerable virtue of this concept of feeling is that it comes with a metaphysic that can relate mind and body. Writes Langer, "Instead of looking for a point of liaison between the brain and the mind, we may look for a psychical limen in the rise and abatement of cerebral processes." [1967, p. 31]. The key to this process is feeling. All knowing first registers in feeling. Again, from Langer, "Feeling stands ... in the midst of that vast biological field which lies between the lowliest organic activities and the rise of mind. It is not an adjunct to natural events, but a turning point in them." Langer, 1967; p. 32 [see also Philippe, cited in Langer, pp. 94-85]. Because feeling consists of organic processes in psychical phase, it is explained ultimately by the bodily process of which it is an appearance. ${ }^{4}$ The physiology of feeling spans a continuum of organized activity, ranging from physiochemical interactions at sensory interfaces; to branching chains of activity in somatic, muscular, and neural sub-assemblies; to more organized activity that takes on a primitive psychical phase of inchoate feeling; to the highest orders of activity in the neo-cortex associated with consciousness and symbolization.

\section{FEELINGS 'IN' AND FEELINGS 'OF' SOCIAL LIFE}

The sense of society is a feeling; a psychical moment or phase of experienced society. More particularly the sense of society is a feeling of life, and this in two related respects. First, and as just described, being a feeling it is a psychic phase of the living body. Second, and as will become clearer as we proceed, what is felt is embodiment of the vitality of society. Society is a living form known to us as a feeling of our living bodies.

Although feelings are widely acknowledged in social science, rarely are they identified with society. Typically they are feelings in society rather than feelings of society. The object of feeling is a person, usually the leader, and not the social whole. For example, Homans (1950) conceived of feeling, or 'sentiment', as one aspect of group life. A sentiment is an internal state of a person in relation to other persons in the group. For Homans, the aspect of sentiment, together with the aspects of 'activity' and 'interaction', comprise a framework for analyzing groups. ${ }^{5}$ Heider (1958) regarded the pattern of feelings of group members for one another (i.e., their sentiment relations) as one of the two basic forms of social organization, the other being the grouping of those members (i.e., their unit relations). One of Heider's principal hypotheses was that both sentiment relations and unit relations tend toward balanced states in which there is minimum strain between persons. Social forms exist when people who like one another are together and are separated from those they dislike (i.e., when sentiment relations correspond with unit relations). Going beyond Heider, Heise 
(1979) proposed that all social behavior is based in the psychology of feeling. People act toward others in ways that maintain the feelings they have for them. Social behavior is what people do to maintain sentiments toward others. In this system, which Heise calls the Affect-Control System, sentiments are the signals which control social behavior. Throughout the thinking of Homans, Heider, and Heise, is the notion that social life is a product of feeling (either as a logical product or emergent development). Society is people acting to preserve feelings for one another in a balanced system.

Whereas psychologists tend to see social life as derivative of individual feelings, sociologists and anthropologists tend to see individual feelings as derivative of social life. These latter writers argue that the possibilities of human feeling are determined in society as a collateral fact of social structure. This 'sociogenesis' of feeling can be seen in Marx where he writes of the effect of social contact, which "... begets in most industries an emulation and a stimulation of the animal spirits that heighten efficiency of each individual workman" (in Albrow, 1992, p. 315). Animal spirits have been a frequent touchstone in writings on mass psychology. Le Bon (1896/1960), for example, inspired generations of social scientists with his writings of the changes in individuals brought about under certain conditions of crowd organization. "The fact that [people] have been transformed into a crowd," he maintained, "puts them in possession of a sort of collective mind which makes them feel, think, and act in a manner quite different from that in which each individual of them would feel, think, and act were he in a state of isolation." (p. 6). This is "a special state which much resembles the state of fascination in which the hypnotised individual finds himself in the hands of the hypnotiser." (p. 11). This state is elicited, says Le Bon, as a surfacing of unconscious feelings, passions, and instincts that are common to a people. "It is precisely these general qualities of character, governed by forces of which we are unconscious, and possessed by the majority of the normal individuals of a race in much the same degree... that become common property." (p. 8).

A more articulated sociogenesis of feeling can be traced in Elias' (1936/1978) history of table manners in the West dating from the Middle Ages. With changes in social form came changes in feeling:

People who ate together in the way customary in the Middle Ages, taking meat with their fingers from the same dish, wine from the same goblet, soup from the same pot or the same plate, ...--such people stood in a different relationship to one another than we do. And this involves not only the level of clear, rational consciousness; their emotional life also had a different structure and character. Their affects were conditioned to forms of relationship and conduct which, by today's standard of conditioning, are embarrassing or at least unattractive. What was lacking in this courtois world, or at least had not been developed to the same degree, was the invisible wall of affects which seems now to rise between one human body and another, repelling and separating, the wall which is often perceptible today at the mere approach of something that has been in contact with the mouth or hands of someone else, 
and which manifests itself as embarrassment at the mere sight of many bodily functions of others, and often at their mere mention, or as a feeling of shame when one's own functions are exposed to the gaze of others, and by no means only then [pp. 69-70].

The idea that feelings such as embarrassment and shame are socially conditioned is reprised in Scheff's (1990) theory of microsociology. Scheff's premise is that people need to feel they belong, that they are included in a web of secure social bonds. This need is supported, he argues, by two primary social emotionspride and shame--which together regulate social life by signalling intact and threatened social bonds respectively. It is interesting that Scheff connects feeling to the social bond as a phase principle; an idea of feeling that recalls Langer. Pride and shame, he writes, are "continuous signals of the state of the bond, an instant readout of the 'temperature' of the relationship" (p. 16).

Continuing work on the effects of society upon individual feeling and behavior appears in sociology under the rubrics of deviance, alienation, role theory, and emotion work, and in psychology under the headings of deindividuation, socialization, adjustment, and social facilitation. Some of this work concerns the plight of man in the modern and now post-modern world. What becomes of the individual in the lonely crowd? But there are strains with less of a bent. Psychologists have studied the means by which society influences the individual, rather than the ends of that influence. McDougall (1920), for example, explored the mechanisms of emotional contagion in groups under a concept he called the "principle of direct induction of emotion by way of the primitive sympathetic response" (p. 24). Zajonc (1965) demonstrated that the simple presence of others promotes instinctive or well-learned behavior (so called 'dominant responses') and retards learning and problem solving. The cause, he speculated, was sociallyinduced arousal. And, in what is perhaps the surest affadavit of the social basis of feeling, there is a growing body of research which treats of the emotional and developmental consequences of social deprivation. One finding is that individuals reared in isolation or deprived of social contact (e.g., as a result of prison confinement), are prone to isolation stress; a syndrome of elevated adrenocortical functioning, fear, unhappiness, abnormal social development, and even morbidity. Social and emotional life are evidently connected.

Nothwithstanding their opposed views of the causal relation between social form and feeling, social scientists generally regard feeling as a phenomenon in the group rather than as a phenomenon of the group. So-called group feelings are in fact personal feelings. They are feelings of liking or animus for other persons, or they are ego-centric feelings of shame, embarrassment, and pride, or they are attitudes passed from person to person in a kind of psychological contagion. They are not feelings of society.

The social feeling to which we are striving can be glimpsed in the work of Durkheim (1915), Freud (1923/1959), Turner (1974), and Brown (1959). In their ideas of 'collective effervescence', 'libido', 'spontaneous communitas' and 
'unconscious feelings of mankind', respectively, one finds intimations of feelings of the social whole (Sandelands \& St Clair, 1993), albeit intimations that remain largely unconceptualized. Because the ideas of Freud and Durkheim are especially instructive for the conceptual development which follows, we take time to review them.

\section{Freud's Feeling of the Group}

Freud conceived of the group as an organization of instinctive libido. The ties upon which a group depends are of the character of sexual instincts that are inhibited in their aim (Freud, 1923/59). The group grows out of the human instinct to unite with and incorporate others. This process begins with group members forming a strong emotional identification with a leader. In a collateral development, they form emotional ties with one another by sublimating the envy they feel in competing for the attentions of the leader. This envy (which is analogous to sibling rivalry) is transformed into mutual regard by projecting its hateful aspect outward, away from the group, and onto enemy outgroups. Social structure for Freud is libidinal structure. What the group member feels of a group are his/her ties with other group members.

Perhaps the most interesting feature of Freud's social psychology is its refusal to delineate the personal from the social. The tensions and dynamisms that constitute the individual psyche are the same tensions and dynamisms that define the group. The individual and the group have the same organic form. Social relations express individual psychodynamics which express social relations. Acts, ideas, and feelings of the individual are acts, ideas, and feelings of the group, and vice versa. On the very first page of his Group Psychology and the Analysis of the Ego (1923/1959) Freud notes that "... only rarely and under certain exceptional conditions is individual psychology in a position to disregard the relations of this individual to others. In the individual's mental life someone else is invariably involved, as a model, as an object, as a helper, as an opponent; and so from the very first, individual psychology, in this extended but entirely justifiable sense of the word, is at the same time social psychology as well." Later, and having warmed to the task, Freud submerges the personal into the social even further, finding its origins in humankind's presumed archaic history as a horde animal.

Thus the group appears to us as a revival of the primal horde. Just as primitive man survives potentially in every individual, so the primal horde may arise once more out of any random collection; in so far as men are habitually under the sway of group formation we recognize in it the survival of the primal horde. We must conclude that the psychology of groups is the oldest human psychology; what we have isolated as individual psychology, by neglecting all traces of the group, has only since come into prominence out of the 
old group psychology, by a gradual process which may still, perhaps, be described as incomplete. (pp. 70-71)

In his later writings on society and culture Freud gropes for a psychology that unifies individual and group. For example, in Moses and Monotheism (1939) he claims that societies exhibit a dynamic psychology essentially like that of the individual. This can be seen particularly in the case of religion (a favorite subject of Freud's), which he describes as a group phenomenon analogous to individual neurosis. In religion, Freud finds the same early trauma, the same dynamic of repression, and the same return of the repressed. He illustrates these dynamics with the history of modern Judaism, contending that it is a return of a repressed Mosaic monotheism that originated in Egypt. The key point for Freud is that the histories of society and individual are not just similar or coincident; each requires the other to be interpreted. The neurosis that is social history rests upon an individual psychology that can be understood only in the light of social history. More than anyone before or since, Freud blurs the boundary between individual and social, to the point almost of making it impossible to give priority to either one. In so doing, he suggests the possibility of a dynamic psychology of the group. He opens the door for a concept of society based on feeling. ${ }^{6}$

However, Freud never quite accepted his own entreaties for a group psychology co-equal and co-eval with individual psychology. And he never achieved a conception of the group as a felt whole. Despite its implied autonomy, group psychology always reverted to individual psychology. Probably Freud could envision the autonomous group. Indeed, Brown (1966) has argued that Freud, in his last works on society and culture, conceived of the unconscious as collective; as a possession of all mankind. According to Brown, Freud even considered the possibility that the true psychic reality is collective, and that individual psychology is but a derivation from this collective reality. Perhaps, but this conception could not be reconciled with a life's work that began with the individual mind and its psychodynamics. Even in Moses and Monotheism, wherein Brown finds this possibility expressed, it is the individual not the group who has a living psyche, the individual not the group who turns to ideas such a religion or culture as a check upon his/her neuroses, and the individual not the group who harbors the memory of humankind's ancient phylogenetic history (and this by an unspecified Lamarkian inheritance of ancestral experiences). ${ }^{?}$ According to Freud it is only through the individual's unconscious memory of this ancestral history (his/her possession of the collective unconscious) that a bridge is forged between individual psychology and mass psychology (Freud, 1937, p. 128). Thus and although Freud went farther than most to acknowledge the group as a primary unit of analysis, and farther than most to point out its organic and psychic unit his view from the standpoint of the individual kept him from appreciating fully the feeling qualities of groups that transcend the individual ego. 
Durkheim's Feeling of the Group

Central to any idea of a feeling of society is the presumption of a realm of fact beyond the individual. It was Durkheim $(1915,1933,1982)$ who did the most to argue for such facts. According to Durkheim, ideas such as cooperation, division of labor, social currents, religion and even suicide name realities of society as a whole. Furthermore, such social facts are primary and from them follow all facts about individuals. Thus in the example of cooperation:

With autonomous individualities, as are imagined, nothing can emerge save what is individual, and, consequently, cooperation itself, which is a social fact, submissive to social rules, cannot arise. Thus, the psychologist who starts by restricting himself to the ego cannot emerge to find the non-ego... Collective life is not born from individual life, but it is, on the contrary, the second which is born from the first. (Durkheim, 1893/1933; p. 279).

Durkheim conceived of society as a natural fact. It is an order of nature, sufficient unto itself, and sure as any order identified in psychology, biology, chemistry or physics (Durkheim, 1982). What is more, the social order supervenes over the natural order described in psychology, and indeed over the natural orders described in biology, chemistry and physics as well. How people think and act, their choices of mates and ecological niches, their anatomy, physiology, chemistry and physics are all influenced by their participation in society. The fate of atomic particles in the body is tied to body chemistry, body chemistry depends on physiology and anatomy, both of which are linked to psychological processes of thought, feeling and action, which in their turn are shaped by the organization of society. Thus, to understand human behavior, according to Durkheim, it is not enough to understand psychology. Behavior is not primarily psychological. One must know how psychology is determined by the social order. $^{8}$ The essence of the social order is the moral authority it exerts upon the individual. The social order is the given whole in terms of which individual psychology can be comprehended. ${ }^{9}$

The insight that the social determines the psychological, which appeared in his doctoral dissertation and later published as The Division of Labor in Society (1893/1933), led Durkheim in later works to the surprising conclusion that all human sensibility and mental life arises in society as a consequence of its form and organization (Durkheim, 1915). Feeling and conception, says Durkheim, are intrinsically collective; they originate in and are explained by the morphology of the group, i.e., how it is founded and organized. ${ }^{10}$ As evidence for this conclusion he presents studies of the primitive societies of North American Indians and Australian aborigines which find strong correspondence between their systems of classification and their systems of organization. Of the Australian societies he writes: 
For the Australian, things themselves, everything which is in the universe, are part of the tribe; they are constituent elements of it and, so to speak, regular members of it; just like men, they have a determined place in the general scheme of organization of the society. "The South Australian savage," says Fison, "looks upon the universe as the Great Tribe, to one of whose divisions he himself belongs; and all things, animate and inanimate, which belong to his class are parts of the body corporate whereof he himself is a part." As a consequence of this principle, whenever the tribe is divided into two phratries, all known things are distributed between them. "All nature," says Palmer, in speaking of the Bellinger River tribe, "is also divided into class [phratry] names. ... The sun and moon and stars are said ... to belong to classes [phratries] just as the blacks themselves." ... Nor does the classification stop here. The men of each phratry are distributed among a certain number of clans; likewise, the things attributed to each phratry are in their turn distributed among the clans of which the phratry is composed. (p. 166)

Later, in recapitulating this argument, Durkheim concludes:

... these systematic classifications are the first we meet in history, and we have just seen that they are modelled upon the society organization, or rather that they have taken the forms of society as their framework. It is the phratries which have served as classes, and the clans as the species. It is because men were organized that they have been able to organize things, for in classifying these latter, they limited themselves to giving them places in the groups they formed themselves. And if these different classes of things are not merely put next to each other, but are arranged according to a unified plan, it is because the social groups with which they comingle themselves are unified and, through their union, form an organic whole, the tribe. The unity of these first logical systems merely reproduces the unity of the society. Thus we have an occasion for verifying the proposition which we laid down at the commencement of this work, and for assuring ourselves that the fundamental notions of the intellect, the essential categories of thought, may be the produce of social factors. The above-mentioned facts show clearly that this is the case with the very notion of category itself. (pp. 169-170)

However, in showing that society is prior to category systems such as language, Durkheim complicates the question of how society is known. Societies cannot be categorically perceived, as this presumes a prior category system which, as Durkheim was at pains to show, only emerged as a result of social organization. The Australian aborigines of Durkheim's examples must have had prior conceptions of their social life - of clan, phratry and class-that were not originally categorical or linguistic, but which became so with the elaboration of social life. As Durkheim (1893/1933) himself notes, what is first in perception is often last in fact. The correspondence between social categories and language categories may explain where the language categories came from but it leaves unanswered how social categories were known to these tribespeople in the first place. Before conceding Durkheim's point that social facts are primary and real (Durkheim, 1982), we must say how they became known.

Durkheim offers few clues about how social facts are known. His definition of social fact suggests a procedure for detecting traces of such facts, though not the facts themselves. A social fact is "any way of acting, whether fixed or not, capable of exerting over the individual an external constraint; which is general 
over the whole of a given society whilst having an existence of its own, independent of its individual manifestations." (Durkheim, 1982; p. 59). Social facts are evidenced by their effects on individuals, to whom these facts are experienced as constraints. Thus, the anomic social form is reflected in the rate of suicide. The crowd is reflected in feelings of excitement or effervescence. And religion is reflected in the sense of the sacred (Durkheim, 1915). Although a focus on effects of social facts offers an objective basis for social research, it does not elucidate those social facts. For example, from the fact that people feel a certain way in a crowd it can only be inferred that a social entity is operating behind the scene. Moreover, this inference is problematic because it requires ruling out rival inferences; an inductive process that cannot produce logical certainty. And in any case, inferring the presence of a crowd is not the same thing as experiencing it first-hand. ${ }^{11} \mathrm{~A}$ simple experience requires no inference; the crowd is seen for what it is. Seeing and inferring are different operations, and only the former affords unambiguous evidence of an object. The one is an experience and the other an explanatory principle, and as these have different uses they mean different things. Whereas experiences predicate a subject (who does the experiencing), explanatory principles do not. The experience of a red apple implies a perceiving subject of which it is separate and distinct, but the concept of a gravitational force that brings the apple to earth does not. By being experienced, the red apple is substantiated in a way that the force of gravity is not. The apple can be pointed to and verified by others. This contrasts with the force of gravity which cannot be experienced directly, and for this reason cannot be made into an object. Rather, gravity must be inferred from collateral evidence of its supposed consequences, such as mass attraction and the feeling of weight. Aj long as social facts are likewise operationalized as explanatory principles they cannot be the 'things' that Durkheim says they are. What is needed is a scheme for bringing social facts into experience so that they can be objects of scientific study.

The only idea open to us is to suppose a pre-categorical or pre-linguistic conception or feeling of society from which an articulated categorical conception of society could arise. Somehow perceivers must be able to intuit the whole, to feel its presence, as a precondition for delineating its elements and structure. Freud opens us to this possibility by his suggestion of an association bordering on identity between individual psychodynamics and social relations. Unconscious feelings of society are integral elements of the individual psyche. His fundamental principle of repression is an opposition of societal values and individual instincts and concerns. Society is represented psychically in the office of the Ego, and especially its bureau of the Super-Ego or Ego-Ideal. The biologic individual is represented by the office of the Id. These warring departments are largely unknown to the individual who senses them, if at all, only as vague feelings of conflict or anxiety. But as we have seen, Freud was not in a position to develop this insight into a conception of social forms based upon feeling. 
Durkheim likewise intimates of pre-linguistic feelings of social form, although he too shies away from making them the focus of inquiry. In his study of the religious idea among the Australian aborigines, Durkheim (1915) demonstrates how the totemic principle identifies the clan with a divine reality; this reality being none other than the clan itself. Like a god, the clan is a being whom men think of as superior to themselves and upon whom they feel they depend. The clan pursues ends which are special to it and which require its members forget their own interests and act as its servitors (p. 237). In this formulation we find a striking resonance with Freud's idea of the individual psyche as involving unconscious feelings of society. Durkheim likewise accords psychic significance to an unconscious collective power.

The man who has done his duty finds . . . a feeling of comfort, of which he does not ordinarily take account, but which sustains him, none the less. The sentiments which society has for him raise the sentiments which he has for himself. Because he is in moral harmony with his comrades, he has more confidence, courage and boldness in action, just like the believer who thinks that he feets the regard of his god turned graciously towards him. It thus produces, as it were, a perpetual sustenance of our moral nature. Since this varies with a multitude of external circumstances, as our relations with the groups about us are more or less active and as these groups themselves vary, we cannot fail to feel that this moral support depends upon an external cause; but we do not perceive where this cause is nor what it is. So we ordinarily think of it under the form of a moral power which, though immanent in us, represents within us something not ourselves: this is the moral conscious ... (p. 242)

Significantly, Durkheim proposes that this godlike collective power is known as a feeling. Obedience to moral authority, which is recognized in the clan, does not result from perceptions of the clan's wisdom, but from "a certain sort of physical energy" (p. 237) immanent in the idea of the clan. More particularly, "( $r$ )espect is the emotion which we experience when we feel this interior and wholly spiritual pressure operating upon us" (p. 238). As evidence of the unique feeling of the group, Durkheim cites several examples, one of which may be familiar to anyone who has spoken to a large gathering.

This is the explanation of the particular attitude of a man speaking to a crowd, at least if he has succeeded in entering into communion with it. His language has a grandiloquence that would be ridiculous in ordinary circumstances; his gestures show a certain domination; his very thought is impatient of all rules, and easily falls into all sorts of excesses. It is because he feels within him an abnormal over-supply of force which overflows and tries to burst out from him; sometimes he even has the feeling that he is dominated by a moral force which is much greater than he and of which he is only the interpreter. It is by this trait that we are able to recognize what has often been called the demon of oratorical inspiration. (p. 241)

Thus we find in Durkheim the core of the idea that society enters awareness as feeling. It is a feeling of society, not in society, that dominates the perceiver and that exerts moral authority upon him/her. In the example of the Australian 
aborigine, this feeling finds expression and a kind of release in the totem, which is an objectification of this feeling.

It is unfortunate that having established the basis of society in feeling, Durkheim does not pursue or develop this insight in any detail. Indeed, by his method of sociology feelings are taken to indicate only the presence of unsurveyable social forms. The reason for mythological systems of interpretation such as totemism, he argues, is because people cannot see the social fact they feel. "(S)ocial action follows ways that are too circuitous and obscure, and employs psychical mechanisms that are too complex to allow the ordinary observer to see when it comes." (p. 239). The possibility is not considered that the feelings themselves hold clues to the forms of society they manifest - that they are not simply indicators, but are the thing indicated as well. This could be explained perhaps by Durkheim's notorious aversion to that which cannot be measured objectively. Elsewhere he says this of the use of feelings as a basis for social science:

Feelings relating to social things enjoy no pride of place over other sentiments, for they have no different origin. ... They are a product of human experience, albeit confused and unorganized. They are not due to some transcendental precognition of reality, but are the result of all kinds of disordered impressions and emotions accumulated through chance circumstance, lacking systematic interpretation. Far from bringing elightenment of a higher order than the rational, they are composed exclusively of states of mind which, it is true, are strong but also confused. To grant them such a predominant role is to ascribe to the lower faculties of the intelligence supremacy over superior ones and to condemn oneself more or less to a rhetorical logomachy. A science constituted in this way can only satisfy those minds who prefer to think with their sensibility rather than their understanding, who prefer the immediate and confused syntheses of sensation to the patient, illuminating analyses of the reason. Feeling is an object for scientific study, not the criterion of scientific truth. $(1982, p .74)$

Of this dim view of feelings taken by Durkheim, two points should be made. First, and to paraphrase Shakespeare, perhaps Durkheim doth protest too much. The force of this reaction against emotional sensibilities and in favor of a hard and fast reason suggests a repressed connection between them in Durkheim's thinking. As emotion and reason are not opposed in fact, but are everywhere interpenetrating, only a mighty effort could keep them apart. Second, it bears repeating that it is Durkheim's own reasoning that leads to the surmise of a preconceptual and prelinguistic understanding of social form. In so far as the human intellect is a product of social organization it could not at the same time be the original basis of our knowledge of that organization. Somewhere along the line a more primitive understanding of social form must be admitted into the picture. This primitive understanding is argued here to be of the nature of a feeling; a feeling of social form. It is further argued here to be of prime significance for social science.

And so it is that Freud and Durkheim, two turn-of-the-century contemporaries who it seems were unaware of each others work, can be brought together to 
suggest a direction for social science that is yet to be developed in full. Although implicit in their thinking, it is a direction neither could himself take, in Freud's case because he could not abandon the individual to see society clearly as a separate and higher order of nature, and in Durkheim's case because he could not find enough reason in feelings to trust them as a focus of inquiry into this higher order of nature. However, by combining the insights of these two giants of human studies with those of philosophers of nature such as Whitehead and Langer, we can glimpse the possibilities of this line of study.

\section{FEELINGS OF SELF AND FEELINGS OF SOCIETY}

In charting the feelings of social life it is important to distinguish between feelings of self and feelings of society; the two being often conflated in experience and thought. A feeling of self refers to a relation of ego and other. A feeling of society, on the other hand, refers to the form of social life, which may not include ego as an element (and may not include even persons as elements). In making this distinction we follow Durkheim rather than Freud. As we have seen, whereas Durkheim distinguishes society from individual as a separate realm of experience and fact, Freud identifies both with the relation of ego and other and thus conflates the experiences of them both. In Freud one can see society in individual psychodynamics; its brooding presence is a constant reminder of the person's two-fold nature as individual organism and social animal. But in Freud one cannot see the society itself, as a whole, and that is where our interest lies. We focus on feelings of society because these are most telltale of human social life. From such feelings the basic forms of social life can be discerned.

The difference between these two types of feeling is the difference suggested by Langer (1962) between feelings of an individuated social life and feelings of an integral social life. The human animal, according to Langer, is unique in its degree of individuation. As a symbol-using creature, it is able to occupy worlds of meaning of its own making, worlds beyond the literal here and now lived by other animals. This symbolic capacity engenders self-awareness and the need, unprecedented in the animal kingdom, for self-realization. Thus, when the human animal participates in society, it does so unlike any other animal-it participates as a self-possessed individual who may or may not go along with the group. Viewed in this way, writes Langer, human society is not an integral organism, but an organization of individuals. However, opposing individuation is an older, vestigial feeling of identification with the species, that Langer joins us in calling the "sense of society". Viewed in this way, human society retains an organic quality that can be compared to that of other social species. These two feelings, of an individuated social life (here called 'feelings of self') and of integral society (here called 'feelings of society'), comprise a dialectical relation that animates human society and perplexes theories of social life. 
A similar distinction was drawn many years earlier by Toennies (1879/1957). Toennies contrasted the Gesellschaft society, which he conceived as a society of individuals, and the Gemeinschaft society, which he conceived as an organic whole. The Gesellschaft is an artificial aggregate comparable to Langer's organization of individuals. There is no a priori and necessary unity; no actions which manifest the will and spirit of the totality. Organization is economic; everybody is by him/herself and connected to others through exchanges of goods and services. Its signature feeling is aloneness in a world of self-interest. The Gemeinschaft, in sharp contrast, is a real organism founded upon mutual affirmation of wills. It is that kinship which exists against and exclusive of individual identity and self-interest; the feeling Langer called our sense of society. For Toennies and Langer both, the Gemeinschaft is the older and more essential of the two feelings, the Gesellschaft being a late consequence of industrialization and urbanization.

With the Gemeinschaft comes awareness of the society as a whole, as a being. Simmel (1971) connects this awareness with the concept of good form. In a good form elements are mutually defining and interact to form a unity. This concept recalls Langer's (1967) definition of living form as a dialectical patterning of act elements comprising an irreducible whole. This concept also recalls the idea of pregnanz in Gestalt psychology which is likewise a principle of 'good form'. Part of what defines a Gestalt is the participation of its elements in an integral form (e.g., a symmetric or regular geometric figure; a harmonious melody). Pregnanz is that whole-property of a form that pervades its constituent elements; that property Wordsworth called its 'brooding presence'. A pregnant form, therefore, is one which commands its own meaning and lends that meaning to its parts.

It is the organism of the Gemeinschaft we feel. Organism is for us a good form and perceptible as such. However, with the Gemeinschaft, as with all other good forms, comes the possibility of describing it in terms of its parts. As Toennies has pointed out, this organic totality resists scientific analysis:

... the tendencies and inevitableness of onganic growth and decay cannot be understood through mechanical means. In the onganic world the concept itself is a living reality, changing and developing as does the idea of the individual being. When science enters this realm it changes its own nature and develops from a logical and rational to an intuitive and dialectic interpretation; it becomes philosophy. (p. 193)

Asch (1952) refers to the feeling of society as one of "atmosphere" and notes that it is both vivid and difficult to define (p. 225).

With the Gesellschaft comes awareness of self, awareness of other, and awareness of the relation between the two. Persons who are the origins and objects of social activity, and social life becomes a network of related individuals. Consciousness turns from the society as a whole to its parts; to the self and others. This is a transformation of emotional sensibility; a new order of feeling. 
As feelings go, the feeling of self is surely one of the most complex and least understood; at times pleasing, as in the feeling of being a vital person in the world; at times ambivalent, as in feelings of self-esteem (for better or worse); and at times despairing, as in the feeling of loneliness or alienation. ${ }^{12}$ It is in any case the first and most significant alternative to the sense of society. As it waxes the sense of society wanes.

Feelings of self belong to a sensibility not of integral society, but of an arrangement of individuals. No longer a unitary form, no longer a good form, society is a theoretical idea, an abstraction. It is an idea that stands-in for older feelings of organism, but supplies none of the former's substance. Perhaps this is why the Gesellschaft sometimes leaves us at a loss or cold (think of a formal bureaucracy); we who are vital, living beings cannot resonate with an abstract lifeless structure of individuals. We feel it as an absence; as something not there.

The individual psychology born of feelings of self is a significant development in the animal world, limited so far as we know to our own branch of the primate line. In the chimpanzee this psychology appears in rudimentary form, in the capacity to recognize the self in a mirror (see Povinelli, 1993), and in the capacity for self-interested political behavior (see de Waal, 1982). In humans, individual psychology is far more developed, although it appears in varying degrees, depending on the course and extent of cultural development and the maturity of the individual within that culture. In particular, the concepts of self and personal relations appear to be more fully developed in Western cultures than Eastern cultures (Markus \& Kityama, 1991), and more fully developed in late cultures than early cultures (Levy-Bruhl, 1926/1985; Jaynes, 1976; Shanahan, 1992). There is, for an example, the suggestion that the feeling of romantic love, which to the afflicted seems an eternal truth of human experience, is a 13th or 14th century invention of Western culture. Resting as it does upon personal discernment (as Bernard Shaw cruelly puts it, "Love is exaggerating the differences between one woman and another"), this feeling presupposes a developed psychology of personal relations. More generally, romantic love can be seen as a development of cultural ideology of individualism which, according to Shanahan (1992), has had a brief history, commencing in ancient Greece, nurtured and developed mainly in the Judeo-Christian traditions of the West, and approaching its end in post-modernism. ${ }^{13}$

There can be no doubt about the significance of feelings of self in relation to the older feelings of society. With feelings of self comes a new entity in naturethe individual - and with it a new order of social life. As with most developments of nature, there is both good and bad in it. The good is that the human animal can use ideas about the self in relation to others to enact new relationships, thus adding combinatorial flexibility and mutability to society. Individuals can combine and recombine as circumstances or desires change. Further, they can substitute for one another to sustain a pattern of relations even in the absence of particular persons. The bad is that the human animal now has a self to contend with. 
With a self comes self-concern, and with self-concern comes conflict with oneself, conflict with others, and conflict with the social whole. And only a self could feel pride, guilt, anxiety, and existential dread.

The contrast between the feeling of self and the feeling of society also distinguishes Simmel's concept of society from the concept of society argued for in these pages. For Simmel, society is a concept people use to think about their relations with others. There is no object to be felt or seen, only socially aware individuals in a working intersubjectivity. ${ }^{14}$ For us, society is an object experienced as a feeling. The difference between these two conceptions can be seen in their view of a particular social form; such as an exchange relation. Taking the perspective of individual actors, Simmel describes this relation as a trade-off between personal sacrifice and attainment of a personal desire. Exchange is a form of consciousness of the self in relation to others. We take the view that exchange is a totality. This totality is a vital form that involves a polarity of massed values (i.e., goods, currency, favors) that attract one another in varying degrees but cannot trade places except in discrete packets or quanta. Exchange occurs as a consumation of the tension between massed values (in somewhat the same sense as a meal or sexual interlude is a consumation). Our feeling of this dynamism confirms the exchange as an object of the social world; as a society.

Finally, the comparison with Simmel suggests feelings of society are harder to recognize than feelings of self. As the old French proverb has it, 'the fish would be last to discover water'. This is partly, as in the case of the fish, a matter of perspective. It is difficult to see the whole when in its midst. But this is partly also a matter of readiness, the eco-centric perceiver is pressed to see beyond the personal implications of social life. An experience of society requires an observer whose ego does not intrude upon his/her appreciation of the whole. The turn from Simmel could hardly be sharper. He argues that society needs and can have no outside observer; it is a construct. We believe that society is perceptible but only to one unburdened by personal interests. There are, we argue, societies over and above persons, and these are known by different means.

\section{THE SENSE OF SOCIETY}

Having identified the sense of society with feeling, and having distinguished feelings of society both from feelings in society and from feelings of self, it remains to describe the sense of society in positive terms. What is felt in the sense of society? And, how does it feel?

We have seen that society exists as a life, or not at all. A collection of individuals is not alive and is not a society. As emphasized by Langer and Toennies, a collection of individuals is an abstraction; an intellectual construct rather than a thing; an organization rather than an organism. What is felt of 
society is always and everywhere its vital dynamism. Society is felt in moments, large and small -in the electricity of the crowd, in the spirited give and take of conversation, in the drama of the courtroom or operating room, in the mingled expectations of a staff meeting, in the rising hopes of sexual contact, in the contests of sport, and in the familiar grooves of family relations. What unites these and countless other examples of society is a vital interplay of tensions-a living dynamic. In what follows we touch briefly upon three broad feelings that constitute perhaps the largest part of our awareness of society.

\section{Participation}

Perhaps the oldest and most basic feeling of society is participation; the feeling of being a part of a larger corporate body. ${ }^{15}$ Although an aspect of our everyday awareness of social life (e.g., we speak of being a 'member' of a group, thus invoking the metaphor of the body and its parts), this feeling is more acute and easily recognized in the mentality of so-called 'primitives' and children.

Actors in primitive societies often are reported to be oriented more to community than to self; the self being a relatively undeveloped idea in their cosmology. Ianger (1982) describes the psychology of these actors as follows:

\footnotetext{
Every actor ... feels the effort he is putting into the current undertaking more as the power of the working, fighting, or dancing group than of his separate body; through him the power of the whole is flowing. A man's (and even more, perhaps, a woman's) private routine of chores does not evoke enough feeling to make the person so engaged aware of any particular achievement. But in communal work... most persons experience a lift of a general vital feeling... In the most primitive societies this sense seems to be somewhat diffuse and impersonal, like the acts which inspire it; the agent is not really "I, ${ }^{n}$ but "we." The homunculus is not strongly felt as a single being, but at best as a great, continuous power, the Mind of a human tribe, set in the midst of natural forces it seeks to control by thought and magic mastery ... It is the human society whose life is felt by each member as a power streaming through his limbs.
}

Levy-Bruhl (1926/1985) has described the "primitive mind" as operating on the basis of a communal principle in which the perceiver participates in and with what is perceived. Whereas modern (civilized) mind is governed by the law of non-contradiction, in which objects are clearly distinguished and arranged coherently and consistently in logical systems of relations, primitive mind is governed by the law of participation, in which objects are barely distinguished (if at all), are not logically organized, and are seen in terms of their active participation in life and feeling. The primitive, according to Levy-Bruhl, does not distinguish him/herself from the tribe.

Piaget (1968) has written similarly of the animistic thinking of preverbal children, who are likewise prone to confuse group and self. For Piaget this 
mistaken perceptual form expresses "... a confusion or lack of differentiation between the internal or subjective world and the physical universe" (p. 27). He argues that with clearer recognition of the self as object distinguished from other objects and with development of substantial verbal intelligence with which to symbolize objects and relations, animistic thinking is replaced by more articulate and logical thinking.

A not very subtle implication of Levy-Bruhl and Piaget is that animistic thinking is wrong for being unsophisticated. But to say such thinking is unsophisticated is not to say it is unrealistic. A closer look at animistic perception belies the disparaging view taken of it, and shows that view to be scientistic and perhaps even culturally elitist. Recent research in psychology finds substantial animism in adult perceptions, enough perhaps to question whether animistic perception is a passing feature of immaturity. Sheehan, Papalia-Finlay \& Hooper (1981) presented data for 90 subjects, aged 6 to $65+$ years, showing a high frequency of animistic responses in all age groups. These responses were unrelated to classification ability or analytic cognitive style. Seitz \& Beilin (1987) examined responses to physiognomically suggestive metaphors in photographs in 70 children ranging from pre-school to college age and ranging in IQ from medium to high. Young children showed significant levels of physiognomic responding; older and high IQ children showed even higher levels of response. Against Piaget, there are good reasons to think animistic perception is an innate capacity of practical intelligence that develops with use and that is not superceded by more refined perceptions. Not least, animistic perception confers evolutionary advantage where sensitivity to live predators contributes to having more offspring and to raising them to reproductive age.

It is thus interesting to note that communally organized cultures today make bold the very sensibilities that conceive a continuity between actor and social world. Indeed, these sensibilities appear universal, even if more obscure in advanced Western cultures. Markus and Kitayama (1991) develop this point in their contrast of Eastern and Western concepts of the self. Eastern cultures insist:

... on the fundamental connectedness of human beings to each other. A normative imperative of these cultures is to maintain this interdependence among individuals. Experiencing interdependence entails seeing oneself as part of an encompassing social relationship and recognizing that one's behavior is determined, contingent on, and, to a large extent organized by what the actor perceives to be the thoughts, feelings, and actions of others in the relationship. (p. 227)

In contrast, the Western concept of self is characterized by:

... faith in the inherent separateness of distinct persons. The normative imperative of this culture is to become independent from others and to discover and express one's unique 
attributes. Achieving [this goal] requires construing oneself as an individual whose behavior is organized and made meaningful primarily by reference to one's own internal repertoire of thoughts, feelings, and actions. (p. 226)

By its celebration of the individual, Western culture gives shorter shrift to feelings of participation that are equally part of human experience. The social world is portrayed as composed of economic individuals who have no intrinsic connection to others, and who pursue their own economic ends in as rational a manner as possible. To be sure, this view has often been a target of criticism by social philosophers who complain of its dispiriting effects and of its insult to community. Buber (1958), for one, notes the dangerous incompleteness and spiritual vacuity of a world view that puts other persons at a distance from living consciousness. He calls this the 'I-It' relation and contrasts it with the 'I-Thou' relation struck by primitives (and children) who, in concepts such as 'mana', meet the world in a supersensuous awareness of its indivisible integrity. Likewise Brown (1966) offers a paen to mankind's ancient and unconscious feeling of identity with others; a feeling he finds too often missed or misunderstood in today's technologically advanced society:

\footnotetext{
The unconscious is that immortal sea which brought us hither; intimations of which are given in moments of "oceanic feeling"; one sea of energy or instinct; embracing all mankind, without distinction of race, language, or culture; and embracing all the generations of Adam, past, present, and future, in one phylogenetic heritage; in one mystical or symbolical body. (pp. 88 89)
}

Recent years have seen an explosion of interest in the welfare of human communities, much of it reflecting concern about the loss of community feeling to egoism. Despite its histrionic tone, this work is eloquent in showing the feeling of participation to be basic and precious in human experience.

\section{Love}

To the modern adult the sense of society may be most acute in the condition of romantic love, which is, perhaps, partly a response to, and compensation for, the loss of the older feeling of participation described above. In any case, the condition of being in love is notoriously one of solidarity in which boundaries of ego are effaced in oneness of spirit. Lovers are united in an impervious sense of society.

It is far from the aim of this paper to do justice to the condition of love. Suffice it to note that love is a vital social dynamic and a feeling of society. This is plain in Michel de Montaigne's famous essay on friendship, in which he stresses the vital unity and indissolubleness of his friendship with Stephen de la 
Boetie. No casual acquaintance, this friendship melded two souls into an indivisible entity.

... what we commonly call friends and friendships are nothing but acquaintances and familiarities, contracted either by some accident or by convenience, by means of which our souls are held together. In the friendship I speak of, they mingle and merge together with so complete a blending that they efface and can no longer find the seam that joined them. (1588/1949; p. 65)

Montaigne's feeling of society in this friendship is corroborated by his awareness of the loss of individual will and concern:

This [friendship] has no other model than itself and can be compared only with itself. It is no one particular consideration, nor two, nor three, nor four, nor a thousand. It is I know not what quintessence of all this mixture which, having seized my whole will, led it to plunge and lose itself in his; which having seized his whole will, led it, with equal hunger and emulation, to plunge itself into mine. I may truly say lose since we reserved for ourselves nothing that was our own, nor that was either his or mine. (p. 66)

Montaigne's acute sense of society in friendship finds a contemporary echo in the concept of neighborly. love described by the Spaniard, Miguel de Unamuno (1921):

To love my neighbour is to wish that he may be like me, that he may be another I-that is to say, it is to wish that I may be he; it is to wish to obliterate the division between him and me, to suppress the evil. My endeavour to impose myself upon another, to be and live in him and by him, to make him mine- which is the same as making myself his-is that which gives religious meaning to human collectivity, to human solidarity. (p. 279)

According to Unamuno, the 'feeling of solidarity', the sense of society, originates within, as a reflection of the society that is the person. The ' $\mathrm{I}$ ' is a social product, a product of the All that proceeds to God and that is projected from God. For Unamuno, the sense of society comprising love is before all reason and analysis; it is a religious sense.

Finally, even the psychologist Freud (1930/1961) saw in the condition of love the paradigmatic and non-pathological capacity to feel society. This sense of society comes in contrast to our usual sense of ego and yet holds us with equal conviction.

Normally, there is nothing of which we are more certain than the feeling of our self, of our own ego. This ego appears to us as something autonomous and unitary, marked off distinctly from everything else. ... There is only one state-admittedly an unusual state, but not one 
that can be stigmatized as pathological--in which it does not do this. At the height of being in love the boundary between ego and object threatens to melt away. Against all the evidence of his senses, a man who is in love declares that ' $l$ ' and 'you' are one, and is prepared to behave as if it were a fact. (pp. 12-13)

Play

Finally, the sense of society is perhaps most familiar to us as a feeling of play. In the pure and unfettered sociability of play we feel the life of society. For Simmel (1971), play is the social form underlying human society. The feeling of play is the feeling of society (p. 130). And for Huizinga (1950), play is the definitive property of social life. In play, we glimpse the nature and outlines of a social feeling that is older than human civilization, and indeed older than our species. Play is an integral part of our phylogenetic heritage and a key element of our evolution. Play appears widely among the social mammals and is most evident in the highest primates, particularly the chimpanzee and man.

Whereas the play of most mammals consists principally of mock-fighting, that of the highest primates includes imitation, feigning, and even sexual foreplay (de Waal, 1982), and that of humans adds symbolization which greatly increases its plasticity and generativity. Between the child's mannered play of house, her adolescent brother's scramble for esteem in school, and their parents' cocktail party repartee lies a vast range of sociable play. Play has so many faces that it can hardly be said to have an identity of its own. As Shotter (1973) points out, play is such a rag-bag of activities because its forms and functions are more diverse than real life. We play at everything.

We know play as a definite syndrome of activity and feeling. Simmel (1971) sees it as a cluster of reactions around a basic impulse to associatean impulse cognate to art. This impulse "distils, as it were, out of the realities of social life the pure essence of association, of the associative process as a value and a satisfaction" (p. 128). This distillation is marked "by a feeling for, by a satisfaction in, the very fact that one is associated with others and that the solitariness of the individual is resolved into togetherness, a union with others" (p. 128).

Huizinga (1950) describes play by its intensity, absorption, and signature feeling of 'fun'. There is enjoyment in play, even when its subject is serioussuch as in a frank conversation about abortion, a Japanese Tea Ceremony, or a Bar Mitzvah. The most sacred or somber ritual, according to Huizinga, has enjoyments that can be traced to its origins as sociable play. In respect to its pleasures, sociable play offers a further parallel to the activities of art (of art making and art appreciation). The pleasure in art likewise is seldom simple or unambiguous. It may involve an element of undergoing, of reconstruction, which 
may be painful (Dewey, 1934). According to the artist Henri (1923): "To apprehend beauty is to work for it. It is a mighty and entrancing effort, and the enjoyment of a picture is not only in the pleasure it inspires, but in the comprehension of a new order of construction used in its making" (p. 102). The pleasures of play are likewise effortful and nuanced, and for the same reasons. It takes effort to interact fully with others, to be both spontaneous and responsive, and to risk giving oneself over to the interaction to follow wherever it leads. The advice not to discuss sex, politics, or religion in polite company recognizes that these topics are hard to regard playfully.

The subtle emotionality of play, like that of art, perplexes any attempt to explain it. Why are sociable activities pleasurable? And why are their pleasures so varied? According to Simmel, the pleasure in sociable activity is in its satisfaction of a psychological instinct to sociability. But an instinct does not account for the variety of play's pleasures. And in identifying these pleasures as fundamental it fails to explain them. A more revealing answer that does justice to both questions is that the pleasure of sociable play, like that of art, is the pleasure of experienced life. Here we reclaim Langer's (1967) concept of living form and the proposition that living form is known and appreciated as feeling. Sociable play is vital and sensibly alive. It is a social form that exemplifies life for those who behold it. There is pleasure in this identical with the aesthetic pleasure of art. And this is the key to its variety. What is felt in sociable play is a life - a life having its own dynamics and forms, a life that is always unique. What is felt in sociable play is the life of society. Play is the life and the feeling of society.

Play is not only a feeling of society, but its logical basis as well. Play is the creative moment that makes possible the myriad forms of society. "In the union of play and culture," writes Huizinga, 1951, "play is primary. It is an objectively recognizable, concretely definable thing, whereas culture is only the term which our historical judgment attaches to a particular instance" (p. 46). Some of the significance of play can be seen in the infant's development of language, which begins in babbling - a kind of verbal play - and evolves through interaction with others into articulate speech. It has been suggested that the cultural institution of language developed the same way (a case of ontogeny recapitulating phylogeny); beginning in ludic prosody and grunt and evolving by association with mimetic gesture into a system of denotative and later connotative meaning. Huizinga (1950) extends the creative dynamic of social play to encompass virtually the entire domain of human society - including agonistic games, war, law, poetry, philosophy, art, and indeed all of Western Civilization. ${ }^{16}$ "As a culture proceeds," writes Huizinga, "... the play-element gradually recedes into the background, being absorbed for the most part in the sacred sphere. The remainder crystallizes as knowledge: folklore, poetry, philosophy, or in the various forms of judicial and social life. The original play-element is then almost completely hidden behind cultural phenomena" (pp. 46-47). However, this element can be discerned 
in simple cultures and rituals, such as the potlatch of the Kwakiutl Indians of British Columbia or the kula system of the Trobriand Islanders:

The play quality of the "gift ritual" found all over the earth has emerged with singular clarity since Malinowski gave a vivacious and extremely circumstantial acount in his masterly Aggonauts of the Western Pacific, of the so-called kula system which he observed among the Trobriand Islanders and their neighbours in Melanesia. The Kula is a ceremonial voyage starting at fixed times from one of the island groups east of New Guinea and going in two opposite directions. Its purpose is the mutual exchange, by the various tribes concerned, of certain articles having no economic value either as necessities or useful implements, but highly prized as precious and notorious ornaments. ... In the kula they pass temporarily from the possession of one group into that of the other, which thereby takes upon itself the obligation to pass them on within a certain space of time to the next link in the kula chain. ... The whole proceeding is accompanied by all kinds of formalities interspersed with feasting and magic, in an atmosphere of mutual obligation and trust. ... The voyage itself is often adventurous and beset with perils. The entire cultural treasury of the tribes concerned is bound up with the kula, it comprises their ornamental carving of canoes, their poetry, their code of honour and manners. ... Nowhere else, perhaps, does an archaic community take on the lineaments of a noble game more purely than with these Papuans of Melanesia. Competition expresses itself in a form so pure and unalloyed that it seems to excel all similar customs practised by peoples much more advanced in civilization. At the root of this sacred rite we recognize unmistakably the imperishable need of man to live in beauty. There is no satisfying this need save in play. (p. p62-63)

Huizinga sees in play the fundamental group-forming dynamic. Play fosters a feeling of being "apart together" in an exceptional situation, a feeling of sharing something important, and a feeling of mutually withdrawing from the rest of the world and rejecting the usual norms. These are all feelings of connection with others, feelings of groupness. For Huizinga, it is not just that play becomes culture, play is culture. Play is not just in society, society itself is played. ${ }^{17}$

\section{SUMMARY AND CONCLUSION}

The lengthy line of argument developed in this paper can be epitomized in three propositions. First, the sense of society upon which our social life depends is a feeling of life, and this in two related respects. Feeling is a phase principle; a psychical moment of our own living body. And society is a vital form that we embody and thereby feel. Second, the sense of society is a feeling of society. Feelings of society are distinguished from feelings in society and again from feelings of self. And third, the sense of society is largely constituted of feelings of participation, love, and play, which are embodiments of vital social form. Through such feelings, which arise as the psychic phase of social life, society is known as a vital entity.

The argument is still mostly bones and integument, a frail figure lacking blood and muscle. Many questions remain. Not least is how the sense of society relates 
to the sense of self. It has been suggested that these feelings relate as a development, beginning with feelings of society and culminating with feelings of self and others. Feelings march from the primitive to the advanced. Society as individual relations (Gesellschaft) supplants society as organism (Gemeinschaft). Such a progression is suggested by the cultural and historical differences in society noted above, and by traces of the former discernible in the latter. A vestigial sense of society appears in even the most individualistic societies. As Durkheim (1893/1933) observed, absent this sense (what he called 'mechanical solidarity'), orderly individual relations (what he called 'organic solidarity') would be impossible.

The modern sense of self makes a fugitive of the earlier sense of society. To see society today is to exercise an earlier sensibility, a sensibility perhaps more familiar to children and other undersocialized members of society. The adult (especially in the West) hears the dominant chord of individuality, hardly noticing its overtones of organism. Feelings of society which are largely unconscious in everyday life are brought into sharp focus only on special occasions, such as sporting contests, theatrical productions, museum visits, and rare friendships. As Simmel $(1971$, p. 133) points out, true society is today confined largely to artificial worlds:

\footnotetext{
This work of sociability, the only one in which a democracy of equals is possible without friction, is an artificial world, made up of beings who have renounced both the objective and the purely personal features of the intensity and extensiveness of life in order to bring about among themsevles a pure interaction, free of any disturbing material accent.
}

The plainest examples of society are made deliberately strange by devices which mark them of from everyday reality. Play is signified by a characteristic demeanour (in the chimpanzee it is the so-called 'play face') and a galumphing quality (Miller, 1973). In the arts, the concert has its program, the opera or stage play its curtain. Most arts have sacred venues in museums, concert halls, or clubs. Likewise, games of sport are scheduled in special arenas, and have specially appointed umpires and referees to uphold the rules and the boundary between play and the world outside. Such elaborate social conventions confirm an older sense of society easily usurped by egoism. The feeling of play is precious; liable to dissolve at the hint of personal concern. The cultured adult cannot play with the license of a child. Preparations are needed. Boundary-maintaining devices and rules are required to defend activity against disruption. ${ }^{18}$

The sense of society is not less for feelings of self; but lurks in the shadows, as a presence demanding account. Too often social science takes the individual as its starting point for analysis; assuming that society is a product of individual relations, and not the other way around. No doubt this is because individual relations are the first things noticed about social life. But, as Durkheim (1893/ 
1933) warned long ago, what is first in perception often is last in reality. It is a warning we do not often enough heed.

An outstanding problem of social theory is to conceptualize the origins of individual relations; a problem that remains shrouded in mystery. An earlier generation of thinkers sought answers to this problem in an a priori notion of reciprocity. For example, following Durkheim and Malinowski, Gouldner (1960) proposed that individual relations arise in and are made possible by a universal moral norm of reciprocity. This moral norm organizes human relations by making reciprocity its imperative condition:

... beyond reciprocity as a pattern of exchange and beyond folk beliefs about reciprocity as a fact of life, there is another element: a generalized moral norm of reciprocity which defines certain actions and obligations as repayments for benefits received. (p. 170)

... a norm of reciprocity, in its universal form, makes two interrelated, minimal demands: (1) people should help those who have helped them, and (2) people should not injure those who have helped them. Generically, the norm of reciprocity may be conceived as a dimension to be found in all value systems and, in particular, as one among a number of "Principal Components" universally present in moral codes. (p. 171)

Gouldner's idea of reciprocity is topical today as the norm of reciprocity remains the starting point for theories of society. For example, Weick (1969) begins his theory of organizing with the double-interact, a pattern of individual reciprocity. Goffman (1967) constructs a social life as an interaction ritual based upon norms of reciprocity and working consensus. And Axelrod (1984) bases his studies of the evolution of cooperation on the iterated Prisoner's Dilemma game, a game which pits reciprocal relations of defection against reciprocal relations of cooperation. In all of these instances, society is explained by an assumed reciprocity.

For Gouldner and social theorists since, reciprocity is the unanalyzable first fact of social life. The analysis of this paper suggests that the concept of reciprocity is a particular formulation of the feeling of society. On this view, reciprocity is the way society appears to a consciousness that takes note of individuals and relations. Reciprocity is an intellectual abstraction that, like all abstractions, isolates certain features and ignores the rest. In this respect it is a cribbed formulation of society. With it a certain amount of descriptive versimilitude is traded for clarity about contents. Society is seen as a Gesellschaft; a mechanical array of individual relations. Gouldner's mysterious norm of reciprocity is an abstract formulation of the sense of society. ${ }^{19}$

This paper focused on the feelings that comprise our sense of society. Feeling is a sign of social life; a wordless and intuitive understanding of society. Everything else we know about society presupposes a sense of society and would be groundless without it. Abstractions that classify societies or that analyze societies as networks of persons or action are overlays upon this sense. It remains for 
future work to specify how the sense of society can be symbolized and communicated about in scientifically verifiable terms. This is the first and main challenge of contemporary social science.

Lloyd Sandelands

Department of Psychology

University of Michigan

525 E. University Drive

Ann Arbor, MI 48109-1109, USA

Acknowledgements The author thanks Jim Walsh, and the editor and reviewers of this journal for their contributions to this work. Please address all correspondence to Lloyd Sandelands, Department of Psychology, University of Michigan, 525 E. University Drive, Ann Arbor, MI 48109-1109.

\section{NOTES}

1 The uniqueness of this ability is confirmed in recent experiments that find perspectivetaking and formal organization to be limited to the farthest reaches of our own branch of the primate line, including our nearest relative the chimpanzee but no other (see Povinelli, 1993). Whereas chimpanzees can learn to work together in a simple system of roles, rhesus macaques cannot. Tellingly, the same difference appears between $4 \mathrm{yr}$ old and $3 \mathrm{yr}$ old children, suggesting not only that ontogeny recapitulates phylogeny but that the capacity for symbolization may be a critical factor in the constitution of society.

${ }^{2}$ It seems that not even our simian relatives feel our pain. Cheney \& Seyfarth's (1990) study of Old World Vervet monkeys, for example, finds that whereas it is apparent that these monkeys know enough about their societies to discriminate group memberships, discern dominance orders, respect reciprocity, and even form alliances, it is less obvious that they know that they know these things. Absent the latter reflective capacity, they would not have a human-like sense of, or concern for, society.

${ }^{3}$ James (1890) finds in this principle the common wisdom that one can as easily act one's way into a feeling as feel one's way into an action.

There is no more valuable precept in moral education than this, as all who have experience know: if we wish to conquer undesirable emotional tendencies in ourselves, we must assiduously, and in the first instance cold-bloodedly, go through the outward movements of those contrary dispositions which we prefer to cultivate. The reward of persistence will infallibly come, in the fading out of the sullenness or depression, and the advent of real cheerfulness and kindliness in their stead. Smooth the brow, brighten the eye, contract the dorsal rather than the ventral aspect of the frame, and speak in a major key, pass the genial compliment, and heart must be frigid indeed if it do not gradually thaw! (p. 463).

${ }^{4}$ Of course, to say that mind is a phase of organic activity, and thus that it can be described in organic terms, is not to deny that with the rise of a psychical phase other modes of description, such as those of psychology, would be apt or even more useful for some purposes. The dominant conception of mentation today is almost completely divorced from biology. Conception is seen as an information process of classification based on abstracted stimulus features (e.g., Bruner, 1957; Simon, 1992). 
5 Although Homans concentrates upon the feelings or sentiments that group members feel for one another, he also acknowledges feelings of the whole:

The group will be described as an organic whole, surviving and evolving in an environment. We do not just want to get the feel of this whole. We want to be men and understand. $(1950$, p. 10)

Significantly, Homans seems not to regard the feeling of the whole is a valuable datum, perhaps because he finds no room for such an inchoate experience in a manly social science. Yet, his thinking retains a stubborn ambiguity about the group that betrays his own feeling of the whole and provides an overarching rationale and framework for his analysis of the group. In one breath he defines the group as a collection: "a number of persons who communicate with one another over a span of time, and who are few enough so that each person is able to communicate with all the others ... face to face" (p. 1). This group has as its parts individual group members. In the next breath, as we have just seen, he defines the group as a unity: "... the unity that is at the same time a process, the unity whose parts taken separately slip out between our fingers like sand but in integration are as strong as steel" (p. 9). This group has as its parts, not individual group members, but interaction, sentiment, activity, and norms. This latter concept of the group, for which Homans confesses having only a feeling, turns out to be the basis for the system of interdependent hypotheses that he proposes to describe group life. This latter concept of the group, which can barely be stated, let alone measured, conflicts fundamentally with the former concept of the group, which can be stated and measured, but which misleads about the nature of the group.

${ }^{6}$ Following Freud in broad outline, Bion conceived of the group as a product of demands of the ego for self-gratification and for unification with others. Group culture, according to Bion, is that syndrome of feeling and action that arises to cope with these two demands. It is primarily in terms of this culture, and particularly its feeling content, that members know the group. For Stock \& Thelen (1959), Bion's identification of social form and feeling became a principle of method. Their research program was based on two methodological principles: first, that groups must be studied dynamically "... as a continuously modifiable flow within a field of intrinsic and extrinsic forces" (p. 4); and second, that feeling is the basic experience of groups. Feelings are "... direct evidence for diagnosing tensions and the stress conditions that give rise to tensions" (p. 7).

7 Freud's concept of the group as a logical product of individual psychodynamics parallels efforts in sociobiology to conceive the group as an outgrowth of individual or genic self interest. Both adopt an essentialist and reductionist position which locates the individual or gene at the origin of the group. Commentators upon Freud's psychology have made much of this and other parallels, suggesting even that Freud was a proto- or crypto-sociobiologist (e.g., Sulloway, 1979; Leak and Christopher, 1982). Whatever the merits of this suggestion (see, Parisi, 1987), suffice it to note that Freud fails to give account of the group entity for the same reason that sociobiology fails to do so-namely, because the group entity, if it exists, must be a logical ordering beyond individuals or genes.

8 This is not a denial of individual free will, but a problemization of it. Individual will operates within the overarching framework of society and social form. That this is a problem is perhaps nowhere more engagingly illustrated than by the fate of Doestoyevsky's petty bureaucrat, in "Notes from the Underground." As a self defined in society, the Underground Man is compelled by the logic of his situation to undertake great and desperate acts to establish his individuality and free will, ultimately to fail as even the option of going mad can be seen as a response to an all encompassing social order. However, just as psychology suffers the complaint of not giving the social order its due, the residuum left to the individual is the standing problem of sociology. 
${ }^{9}$ Durkheim's concept of social fact is analogous to the concept of Gestalt in psychology and to the concept of mind in some quarters of contemporary neurophysiology. In psychology, a Gestalt is the irreducible perceptual unit in terms of which elementary percepts can be identified as constituent parts (see, e.g., Kohler, 1947). In neurophysiology a mind is the regulative whole which makes sense of neurological activity in the brain (see, e.g., Sperry, 1984).

10 The thesis that mental life begins in social life poses an interesting challenge to the creation of an artificial, human-like intelligence. It suggests that such an intelligence can be fabricated only when thinking machines grow up and get along in human-like societies.

${ }^{11}$ Durkheim was aware of this problem and seemed divided about it. In his preface to the second edition of his The Rules of Sociological Method (Durkheim, 1982), he notes the difficulty in presuming that the contents of individual consciousness are properties of the social fact:

If, as is granted to us, this synthesis sui generis, which constitutes every society, gives rise to new phenomena, different from those which occur in consciousnesses in isolation, one is forced to admit that these specific facts reside in the society itself that produces them and not in its parts - namely its members. In this sense therefore they lie outside the consciousness of individuals as such, in the same way as the distinctive features of life lie outside the chemical substances that make up a living organism. They cannot be reabsorbed into the elements without contradiction, since by definition they presume something other than what those elements contain. (pp. 39-40)

Further, he stipulates as a basic rule of sociological method that:

... when the sociologist undertakes to investigate any order of social facts he must strive to consider them from a viewpoint where they present themselves in isolation from their individual manifestations. (p. 82)

However, having noted the difference between individual representations and social facts he elsewhere asks whether there could not be resemblances between them that justify looking at the former as testimony of the latter.

But once this difference in nature is acknowledged one may ask whether individual representations and collective representations do not nevertheless resemble each other, since both are equally representations; and whether, as a consequence of these similarities, certain abstract laws might not be common to the two domains. (p. 4l)

... in the absence of certainty, it is at the very least probable that, if there exist resemblances between these two kinds of laws, the differences between them must be no less marked. Indeed it does not seem legitimate to claim that the matter from which the representations are formed has no effect upon the various ways in which they combine together. (p. 42)

Such a resemblance is cited when he examines the case of collective emotion:

An outburst of collective emotion in a gathering does not merely express the sum total of what individual feelings share in common, but is something of a very different order... It is a product of shared existence, of actions and reactions called into play between the consciousness of individuals. If it is echoed in each one of them it is precisely by virtue of the special energy derived from its collective origins. (p. 56) 
12 Feelings of loneliness pose an intriguing puzzle. What does the person feel when the feeling of being an individual crowds out a feeling of organism or sociability? What is felt seems to be a lack of some kind, an inchoate yearning for community with others, not as an individual self, but as an element of a comprehensive whole. This may be why it is possible to feel lonely in a crowd, or at the top of a group.

13 There is evidence and argument that the development of self-psychology observed in Western culture is recapitulated in the development of the individual. For Freud, ego development begins with recognition of the mother or caretaker as an object separate from the self, and continues as a process of generalization whereby early object relations are extended to others. For Mead the process was one of social construction in which a 'self' arises as the child takes on the role of others and begins to act toward himself as others do. This role taking, which for Mead takes place early and most often in play, eventuates in the organization of the mature self which consists of a biologically given ' $I$ ' and a socially given 'me' linked in a reciprocal relation. For Freud and Mead the psychology of individual relations is not a biological given, but a development of human society.

14 Asch (1952) adduces a similar concept of social form which defines the group as both product and condition of actions of individuals (p. 251). Like Simmel, he writes: "There are no forces between individuals as organisms; yet to all intents and purposes they act as if there were, and they actually create social forces." (p. 25l) Group action is possible when each individual has a mental representation of the social situation that includes the actions of others and their relations to self, and when these representations of the joint situation are "structurally similar" (p. 252). "These representations and the actions that they initiate bring group facts into existence and produce the phenomenal solidity of group process" (p. 252).

15 There are important questions to be asked about the phylogenesis of this and other feelings of society. As a social animal, we are the evolutionary product of a primate line that diverged some 4 million years ago from the line of our nearest ape relatives. It is likely that feelings of society first made their appearance subsequent to this break, as comparable feelings cannot be identified for other primate species. Further it is likely that the nature of these feelings changed along with the progression from Australeopithicus through the hominid line from Erectus to Habilus to Sapien. With new biological capacities and activities such as bipedalism, encephalization, speech and language come new realms and kinds of feeling. There is an evolutionary psychology of feeling yet to be constituted.

${ }^{16}$ This conception of the generative function of play in the development of society finds parallels in analyses of the development of mind. The primitive mind, wrote Levy-Bruhl (1926/1985), does not experience the world atomistically in terms of distinct and logically classifiable 'things'. Rather, it experiences the world as an interplay of objects or events that embody or convey supernatural powers. These "mystical" objects and events are known, not by immediately given qualities or attributes, but by their felt participation in the dynamic matrix of everyday life. Mentality that has the character of play in the primitive takes a rigorous logical form in the modern.

17 The significance of play as a culture process is lost upon theories of social life that center upon individuals. Freud, for example, barely acknowledges play in his theories of individual and group psychology. Play is a marginal event, a release of energies pent-up by psychodynamics. Thus, jokes and humor reflect a momentary abrogation of the boundary between conscious and unconscious. The Roman Saturnalia and the modern carnival are likewise temporary abridgements of a group formation based on the identification of a leader with the ego-ideal. Freud cannot see the role of sociability in 
the making of society because he is focused on the psychodynamic structure of the individual.

${ }_{18}$ This suggests a departure from the view of Simmel above. Whereas Simmel identifies sociable society as a democracy of equals, which is a particular condition of individual relations, sociable society is seen here as a condition prior to individuals and prior to individual relations. Sociable activity emerges only when personal concerns, including equality, are given up.

19 Adding weight to this interpretation is further evidence in Gouldner (1960) that the moral norm of society is not reciprocity per se, but movement toward reciprocity. To achieve reciprocity would bring society to rest, to a state of self-satisfied fulfilment. Thus, reflecting its origins in organism, this moral norm often seeks a dynamic condition of unfulfilled obligation. Gouldner cites Elgar's study of the Vartan Bhanji ritual in Pakistan and India as an example:

It is notable that the system painstakingly prevents the total elimination of outstanding obligations. Thus, on the occasion of a marriage, departing guests are given gifts of sweets. In weighing them out, the hostess may say, "These five are yours," meaning "these are a repayment for what you formerly gave me," and she then adds an extra measure saying, "These are mine." On the next occasion, she will receive these back along with an additional measure which she later returns, and so on.

Gouldner goes on to remark that maintenance of outstanding obligations can be found in our society as well, in prescriptions which require us not to be overly eager to repay social obligations. This constant dynamism of gift and repayment suggests that it is an underlying dynamic of sociation and organic fulfilment that is being preserved by the moral norm of reciprocity.

\section{REFERENCES}

AlBrow, M. (1992). Sine Ira et Studio - or Do Organizations have Feelings? Organization Studies, 13/3, 313-329.

ARNHEIM, R. (1966). Toward a psychology of art. Berkeley, CA: University of California.

Asch, S.E. (1952). Social psychology. Englewood Cliffs, NJ: Prentice-Hall.

AXFLROD, R. (1984). The evolution of cooperation. New York: Basic Books.

BION, W.R. (1961). Experiences in groups. New York: Basic Books.

BRonowski, J. (1978). The visionary eye. Cambridge, MA: MIT Press.

BROWN, N.O. (1959). Life against death. Middletown, CT: Wesleyan.

Bruner, J. (1957). On perceptual readiness. Psychological Review, 64, 123-152.

Buber, M. (1958). I and Thou. New York: Scribners.

Buck, R. (1985). Prime theory: An integrated view of motivation and emotion. Psychological Review, 92, 389-413.

CAMPBel.L-FIsher, I.G. (1951). Intrinsic expressiveness. Foumal of General Psychology, 45, 3-24.

Cheney, D.L. \& SeyfarTh, R.M. (1990). How monkeys see the world. Chicago: University of Chicago.

de WAAL, F. (1982). Chimpanzee politics. Baltmore, MD: Johns Hopkins.

DEWEY, J. (1934). Art as experience. Reprinted in A. Hofstadter and R. Kuhns (eds), (1964). Philosophies of art and beauty. Chicago: University of Chicago.

DurkhEM, E. (1893/1933). The division of labor in society. Trans. by G. Simpson. New York: Macmillan. 
DURKHEIM, E. (1915). The elementary forms of the religious life. London: Allen and Unwin.

DURKHEIM, E. (1982). The rules of sociological method. Edited with an introduction by S. Lukes, trans. by W.D. Halls. New York: Free Press.

EuIAS, N. (1936/1978). The civilizing process. Trans. E. Jephcott. New York: Urizen.

FESTINGER, L. (1957). A theory of cognitive disonance. Evanston, IL: Row-Peterson.

Freud, S. (1922/1959). Group psychology and the analysis of the ego. Trans. J. Strachey. New York: Norton.

Freud, S. (1930/1961). Civilization and its discontents. Trans. J. Strachey. New York: Norton.

Freud, S. (1939). Moses and monotheism. Trans. K. Jones. New York: Vintage.

GoFFMAN, E. (1967). Interaction ritual. Chicago: Aldine.

GOULDNER, A. (1960). The norm of reciprocity: A preliminary statement. American Sociological Review, 25(2), 161-178.

Hanson, C. (1976). The critical writings of Katherine Mansfield. New York: St Martin.

HARAWAY, D.J. (1991). Simians, cyborgs, and women. New York: Routledge.

HEIDER, F. (1958). The psychology of interpersonal relations. New York: Wiley.

HeISE, D.R. (1979). Understanding events. Cambridge: Cambridge University Press.

HENRI, R. (1923). The art spinit. Philadelphia: Lippincott.

Homans, G.C. (1950). The human group. New York: Harcourt, Brace.

HuIZINGA, J. (1950). Homo ludens. Boston: Beacon.

JAMES, W. (1890). Psychology, Vol. 2. New York: Holt.

JAYNES, J. (1976). The origin of consciousness in the breakdown of the bicameral mind. Boston: Houghton-Mifflin.

KOHLER, W. (1947). Gestalt psychology. New York: Liveright.

LAKOFF, G. (1987). Women, fire, and dangerous things. Chicago: University of Chicago.

I.ANGER, S.K. (1951). Philosophy in a new key. Cambridge, MA: Boston.

LANGER, S.K. (1962). Philosophical sketches. Baltimore, MD: Hopkins.

LANGER, S.K. (1967). Mind: An essay on human feeling, Vol. 1. Baltimore, MD: Hopkins.

LANGER, S.K. (1972). Mind: An essay on human feeling, Vol. 2. Baltimore, MD: Hopkins.

LANGER, S.K. (1982). Mind: An essay on human feeling, Vol. 3. Baltimore, MD: Hopkins.

LEAK, G.K. \& ChRISTOPHER, S.B. (1982). Freudian psychoanalysis and sociobiology: A synthesis. American Psychologist, 37(3), 313-322.

LE BON, G. (1903). The crowd. New York: Holt.

LeVY.BruHL, L. (1926/1985). How natives think. Princeton, NJ: Princeton.

Markus, H. \& KrTayama, S. (1991). Culture and the self: Implications for cognition, emotion, and motivation. Psychological Revieu, 98, 224-53.

McDougall, W. (1920). The grup mind. Cambridge: Cambridge Press.

MEAD, G.H. (1934). Mind, self, and society. Chicago: University of Chicago.

MiLLER, S. (1973). Ends, means, galumphing: Some leitmotifs of play. American Anthropologist, 75(1), 87-98.

Montaigne, M. (1588/1949). Montaigne: Selected essays. Translated by C. Cotton; revised by W. Hazlitt. New York: Modern Library.

PARISI, T. (1987). Why Freud failed: Some implications for neurophysiology and sociobiology. American Psychologist, 47(3), 235-245.

PiageT, J. (1968). Six psychological siudies. New York: Vintage.

Povinelu, D. (1993). Reconstructing the evolution of mind. American Psychologist, 48(5), 493-509.

SANDELANDS, L.E. (1988). The concept of work feeling. Joumal for the Theory of Social Behavior, 18(4), 437-457.

SANDELANDS, L.E. \& ST CLAIR, L. (1993). Toward an empirical concept of group. Joumal for the Theory of Social Behavior, 23(4), 423-458.

SCHEFF, TJ. (1990). Microsociology: Discourse, emotion and social structure. Chicago: University of Chicago Press. 
SCHACTER, S. \& Singer, J.E. (1962). Cognitive, social and physiological determinants of emotional state. Psychological Review, 69, 379-399.

SEITZ, J.A. \& BEILIN, H. (1987). The development of comprehension of physiognomic metaphor in photographs. British Joumal of Developmental Psychology, 5, 321-331.

ShanahaN, D. (1982). Toward a geneology of individualism. Amherst, MA: University of Massachusetts.

Sheehan, N.W., Papalia-Finlay, D.E. \& Hooper, F.H. (1980). The nature of the life concept across the life-span. International Joumal of Aging and Human Development, 12, 1-13.

SheEts-Johnstone, M. (1990). The roots of thinking. Philadelphia: Temple University.

ShotTER, J. (1973). Prolegomena to an understanding of play. Joumal for the Theory of Social Behavior, 3(1), 47-89.

SimMEL, G. (1971). On individuality and social forms. D.N. Levine (ed.). Chicago: University of Chicago.

Smon, H. (1992). What is an 'explanation' of behavior? Psychological Science, 3, 150-161.

SPERRY, R. (1985). In J. Eccles, R. Sperry, I. Prigogine, B. Josephson. Nobel Prize conversations. San Francisco: Saybrook.

STOCK, D. \& ThelEN, H.A. (1958). Emotional dynamics and group culture. New York: New York University for National Training Laboratories.

SullowaY, F.J. (1979). Freud, biologist of the mind. New York: Basic Books.

TOENNIES, F. (1879/1957). Gemeinschaft and gesellschaft. Translated with introduction by C.P. Loomis. Lansing MI: Michigan State University.

TURNER, V. (1975). Liminal to liminoid in play, flow, and ritual: An essay in comparative symbology. Rice University Studies, 60, 53-92.

Unamuno, M. de (1921/1954). Tragic sense of life. New York: Dover.

WhITEHEAD, A.N. (1934). Nature and life. Chicago: University of Chicago.

WiLSON, E.O. (1975). Sociobiology: The new synthesis. Cambridge, MA: Belknap/Harvard.

ZAJONC, R. (1965). Social facilitation. Science, 149, 269-274. 